\title{
On the Importance of the Aromatic Ring Parameter in Studies of the Solvolyses of Cinnamyl and Cinnamoyl Halides
}

\author{
Malcolm J. D’Souza, ${ }^{1}$ Anthony M. Darrington, ${ }^{1}$ and Dennis N. Kevill ${ }^{2}$ \\ ${ }^{1}$ Department of Chemistry, Wesley College, 120 N. State Street, Dover, DE 19901, USA \\ ${ }^{2}$ Department of Chemistry and Biochemistry, Northern Illinois University, DeKalb, IL 60115, USA
}

Correspondence should be addressed to Malcolm J. D’Souza, dsouzama@wesley.edu

Received 2 February 2010; Accepted 19 April 2010

Academic Editor: Daniel Little

Copyright (C) 2010 Malcolm J. D'Souza et al. This is an open access article distributed under the Creative Commons Attribution License, which permits unrestricted use, distribution, and reproduction in any medium, provided the original work is properly cited.

\begin{abstract}
In solvolysis studies using Grunwald-Winstein plots, dispersions were observed for substrates with aromatic rings at the $\alpha$-carbon. Several examples for the unimolecular solvolysis of monoaryl benzylic derivatives and related diaryl- or naphthyl-substituted derivatives have now been reported, where the application of the aromatic ring parameter (I) removes this dispersion. A recent claim suggesting the presence of an appreciable nucleophilic component to the $I$ scale has now been shown, in a review of the solvolysis of highly-hindered alkyl halides, to be unlikely to be correct. Attention is now focused on the application of the $h I$ term for the solvolysis of compounds containing a double bond in the vicinity of any developing carbocation. Available specific rates of solvolysis (plus some new values) at $25^{\circ} \mathrm{C}$ of cinnamyl chloride, cinnamyl bromide, cinnamoyl chloride, $p$-chlorocinnamoyl chloride, and $p$-nitrocinnamoyl chloride are analyzed using the simple and extended (including the $h I$ term) Grunwald-Winstein equations.
\end{abstract}

\section{Introduction}

To commemorate the 60th anniversary of the development of the simple Grunwald-Winstein equation [1], a review detailing its development and applications was recently published [2]. The linear free energy relationship (LFER) shown in (1) was developed in 1948 for the correlation of solvolysis reactions proceeding by an ionization $\left(S_{N} 1+E 1\right)$ pathway [1]. In (1), $k$ and $k_{0}$ are the specific rates of solvolysis of the substrate under study in a given solvent and in the standard solvent, respectively; $m$ is the sensitivity towards changes in the solvent ionizing power $Y$ (initially set at unity for tert-butyl chloride solvolyses), and $c$ is a constant (residual) term,

$$
\log \left(\frac{k}{k o}\right)=m Y+c
$$

It was realized [3] that as the solvolyses of 1- and 2-adamantyl derivatives (Figure 1) cannot be subject to rearside nucleophilic participation and elimination, they could provide improved standard substrates for establishing scales of solvent ionizing power $[4,5]$ and listings of $Y_{\mathrm{X}}$ values are available [6].

For bimolecular $\left(\mathrm{S}_{\mathrm{N}} 2\right.$ and/or E2) reactions, an additional term involving the sensitivity $(l)$ to changes in solvent nucleophilicity $(N)$ is added to (1) to give [7],

$$
\log \left(\frac{k}{k_{o}}\right)=l N+m Y+c .
$$

The development of solvent nucleophilicity scales has been briefly reviewed $[2,8]$ and it has also been reviewed in considerable depth in a book chapter [9]. At the present time, the $N_{\mathrm{T}}$ scale $[2,8-10]$ with $S$-methyldibenzothiophenium ion $\left(\mathrm{MeDBTh}^{+}\right)$as the standard substrate has become the recommended standard [2] for considerations of solvent nucleophilicity.

Three approaches have been proposed to correct for dispersions observed in Grunwald-Winstein plots when aromatic rings are bonded to the carbon that is developing appreciable positive charge at the transition state or when substrates solvolyze with neighboring aryl group participation. Bentley et al. [11] favored the use of $p$-methoxybenzyl 


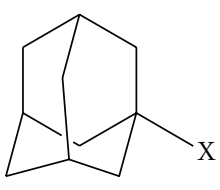

1-adamantyl

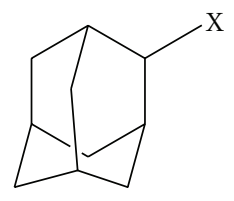

2-adamantyl
Figure 1: 1- and 2-adamantyl derivatives.

chloride as a similarity model to correlate the solvolyses of $\alpha$-aryl halides. Liu and Sheu [12,13] also using a similarity model approach developed $Y_{\mathrm{BnX}}$ scales for each leaving group $\mathrm{X}$ and $Y_{x \mathrm{BnX}}$ scales [14] for $x$ aromatic rings entering into conjugation with the reaction center. Early on, we pointed out [15] that only negligible to moderate improvements result from replacing the $Y_{\mathrm{x}}$ scale by a "specialized" scale and the considerable effort involved in developing the new scales is not justified. Fujio and co-workers proposed [16] a second approach for solvolyses that proceed via anchimeric assistance $\left(k_{\Delta}\right)$ and developed a scale $\left(Y_{\Delta}\right)$ derived from 2-methyl2 -( $p$-methoxyphenyl)propyl toluene- $p$-sulfonate solvolyses. We have favored a third, more general avenue by developing [17] an aromatic ring parameter $(I)$, where an appropriate sensitivity $h$ is added to Grunwald-Winstein equations (1) and (2) to give (3) and (4). This approach avoids the nontrivial task of choosing a closely related similarity model, furthermore, it can be used with multiple aromatic rings in conjugation with the developing carbocationic center, and to correlate solvolysis involving a 1,2-aryl shift [2],

$$
\begin{array}{r}
\log \left(\frac{k}{k_{o}}\right)=m Y_{\mathrm{X}}+h I+c, \\
\log \left(\frac{k}{k_{o}}\right)=l N_{\mathrm{T}}+m Y_{\mathrm{X}}+h I+c .
\end{array}
$$

Recently, Martins and coworkers [18] applied (4) to the specific rates of solvolysis of five moderately-hindered tertiary alkyl halides (substrates mostly with the absence of $\pi$-electrons) and found the sensitivities $(h)$ to changes in the aromatic-ring parameter $(I)$ were sometimes positive and sometimes negative. They suggested that the negative $h$ values arose because $I$ was not a pure parameter and proposed that it included a solvent nucleophilicity component [18]. After a thorough analysis of the available specific rates of solvolyses of 30 highly-hindered tertiary alkyl derivatives, we concluded in a recent review [19] that it appears that the apparent utility of the $h I$ term for substrates not having appropriately placed $\pi$-electrons is an artifact resulting from moderate multicollinearity that is present between the $I$ values and a linear combination of $N_{\mathrm{T}}$ and $Y_{\mathrm{X}}$ values.

Cinnamyl chloride is one of many chemicals that produce allergic contact dermatitis (ACD) in humans [20] and yet it is a common important chemical intermediate that has found use in a variety of pharmaceutical compositions, fragrance, and flavoring agents. The analysis of the substituent effects on carbocation reactivity using the Hammett plot for the chlorine exchange of substituted cinnamyl chlorides [21] and studies of the secondary deuterium isotope effect [22] implied electron-donating conjugation through the double bond in a loose $S_{N} 1$ transition state. Koo et al. have analyzed the solvolytic rate constants and product selectivities $(S)$ of cinnamyl chloride [23] and cinnamyl bromide [24] in a number of binary mixtures of water with ethanol, methanol, acetone, and 2, 2, 2-trifluoroethanol (TFE). The close similarity of solvent kinetic isotope effects, rate-rate profiles of solvent effects on reactivity, and similar selectivity data to $p$-methoxybenzyl chloride $[11,25]$ made the authors conclude that the solvolyses of cinnamyl halides can be explained by product formation incorporating a general base-catalyzed nucleophilic attack on a contact ion pair $[23,24]$. Cinnamyl bromide was subject to electrochemical reduction using cyclic voltammetry and controlled-potential electrolysis [26] where it was shown that the substrate could be reduced to a resonance-stabilized cinnamyl radical, which could further be reduced to a carbanion depending upon the selected potential.

Cinnamoyl derivatives are used to produce compounds that have shown promising antifungal, antibacterial [27], and anticancer [28] activity. Koo and coworkers also studied the solvolyses of substituted cinnamoyl chlorides [29] in aqueous binary mixtures of ethanol, methanol, acetone, and TFE, and in TFE-EtOH. Based on the examination of results obtained using their kinetic data in Hammett plot analysis and in exceedingly scattered Grunwald-Winstein plots, they proposed a dissociative $S_{\mathrm{N}} 2$ pathway for three $p$-substituted cinnamoyl chlorides [29].

\section{Results and Discussion}

In this study, we present specific rates of solvolysis of cinnamyl chloride $(\mathbf{1})$ at $25.0^{\circ} \mathrm{C}$ in three aqueous ethanol $(\mathrm{EtOH})$, three aqueous methanol $(\mathrm{MeOH})$, one aqueous acetone, two aqueous TFE, and four TFE-EtOH mixtures. We reanalyze all available specific rates of solvolysis of cinnamyl chloride (1), cinnamyl bromide (2), cinnamoyl chloride (3), p-chlorocinnamoyl chloride (4), and p-nitrocinnamoyl chloride (5) (Figure 2), in terms of the simple and extended Grunwald-Winstein equations ((1) and (2)), and we also consider the extent to which these equations are improved on incorporation of the $h I$ term ((3) and (4)).

In Table 1, we report specific rate constants at $25.0^{\circ} \mathrm{C}$ for the solvolyses of $\mathbf{1}$ in the aqueous binary mixtures of $\mathrm{MeOH}$, $\mathrm{EtOH}$, acetone, and TFE, and in TFE-EtOH. The specific rate constants for 1 in 97 and 90 TFE- $\mathrm{H}_{2} \mathrm{O}(\% \mathrm{w} / \mathrm{w})$ were determined at 3 different temperatures and an Arrhenius treatment allowed estimation of the specific rate at the higher $25.0^{\circ} \mathrm{C}$ temperature also presented in Table 1 . Our measurements at $25.0^{\circ} \mathrm{C}$, when compared to those reported by Koo and coworkers [23] differ markedly (as shown in Table 1 and corresponding footnotes), by a factor of 5 in pure $\mathrm{EtOH}$, by a factor of 3 in $90 \% \mathrm{EtOH}(\% \mathrm{v} / \mathrm{v})$, and by a factor of 2 in $80 \% \mathrm{EtOH}(\% \mathrm{v} / \mathrm{v})$. Furthermore, an acceptable $2 \%$ difference observed in the value of $80 \mathrm{~T}-20 \mathrm{E}$ progressed to a much larger $30 \%$ difference in the $60 \mathrm{~T}-40 \mathrm{E}$ value, then to a substantial $50 \%$ difference in the $40 \mathrm{~T}-60 \mathrm{E}$ reported value, and culminated in a huge difference of $70 \%$ observed in the 20T-80E mixture. The observations of significant deviations 


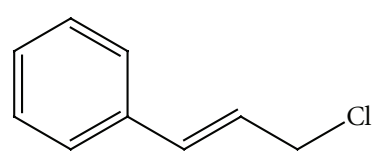

(1)

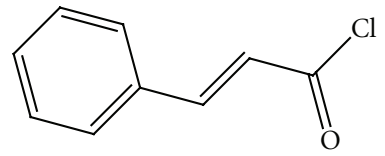

(3)

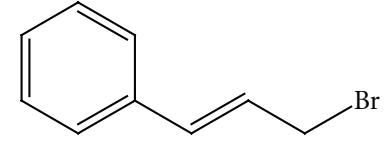

(2)

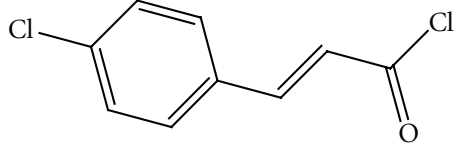

(4)

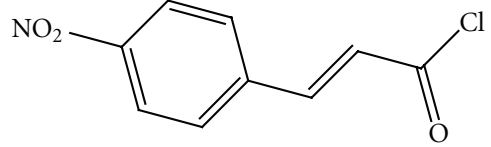

(5)

Figure 2: Molecular structures for cinnamyl chloride (1), cinnamyl bromide (2), cinnamoyl chloride (3), p-chlorocinnamoyl chloride (4), and $p$-nitrocinnamoyl chloride (5).

seen only in EtOH-rich mixtures indicated that the deviant behavior was a general characteristic (in this particular case) of that solvent. We minimized experimental error by designing mechanical mixing for uniform consistency, using ACS reagent grade solvents, repeating the titrimetric procedures using different batches of $\mathrm{EtOH}$, and the key reactions were also repeated during different months to verify that the same trends persisted. The specific rates for the EtOH containing mixtures reported in Table 1 are the averages of at least four independent kinetic runs.

The specific rate constants for solvolyses of $\mathbf{1}$ in solvents other than $\mathrm{EtOH}$ are within an acceptable $\pm 7 \%$ range of values reported by Koo and coworkers [23]. Hence, the new data in the thirteen solvents listed in Table 1 were combined with the nineteen reported values [23] in solvents other than ethanol. As reported in Table 2 for the 32 solvents, we obtained a fair linear correlation using (1), with $m=$ $0.76 \pm 0.03, c=-0.25 \pm 0.08,0.975$ for the correlation coefficient, and 571 for the $F$-test value. Use of (2) leads to an essentially zero $l$ value $(0.09 \pm 0.09)$ associated with a 0.29 probability that the $l N_{T}$ term is statistically insignificant. In contrast, use of (3) displays an $m$ value of $0.79 \pm$ 0.03 , an $h$ value of $0.47 \pm 0.20$ (with a 0.03 probability of insignificance) and with a negligible improvement in the correlation coefficient (0.979) when compared to the solution obtained using (1). As observed in Table 2, analysis of the solvolysis of $\mathbf{1}$ is best carried out in terms of (4), with a considerably higher correlation coefficient of 0.987 , a $l$ value of $0.33 \pm 0.08$, an $m$ value of $0.91 \pm 0.04$, an $h$ value of 0.97 \pm 0.21 , a $c$ value of $0.20 \pm 0.07$, and an F-test value of 340 .

Excluding the data point for $100 \mathrm{EtOH}$, the solvent with highest nucleophilicity and lowest ionizing power (favoring bimolecular reaction); the correlation using equation (4) in the remaining 31 solvents has $l, m$, and $h$ values similar to those obtained with 32 solvents, but with a considerably improved correlation coefficient of 0.992 and a significantly higher $F$-test value of 551. The $l(0.33), m(0.95)$, and $h$ (1.00) values obtained for $\mathbf{1}$ in 31 solvents (Table 2) are very similar to $l=0.25 \pm 0.06, m=0.92 \pm 0.03$, and $h=0.88$ \pm 0.13 , reported for $p$-methoxybenzyl chloride [30]; and $l=$
$0.34 \pm 0.15\left(0.04\right.$ probability that the $l N_{T}$ term is statistically insignificant), $m=0.89 \pm 0.04$, and $h=0.92 \pm 0.15$ for 2,6dimethylbenzoyl chloride [31], where we suggested that the nucleophilic solvation of the developing carbocation rather than a covalent involvement of the solvent molecule, is effective. This affirmation of appreciable nucleophilic solvation for $\mathbf{1}$ as indicated by the $l$ value of 0.33 (in Table 2), is consistent with recent results showing that the $p$-methoxybenzyl carbocation is more stable than the cinnamyl carbocation but less stable than its $p$-methoxycinnamyl analog [32]. These results arose from a synthetic method involving a chlorosulfonyl isocyanate reaction with various alkyl allyl ethers to study carbocation stability in the solution phase, and using this newly developed procedure, the authors also showed that a cinnamyl carbocation is more stable than a benzylic carbocation and less stable than a $3^{\circ}$ carbocation [32]. The $h$ value reported in Table 2 of $1.00 \pm 0.16$ for $\mathbf{1}$ in 31 solvents is also consistent with one aromatic ring easily entering into conjugation [17] with the developing resonance stabilized transition state. This possibility of neighboring $\pi$-bond stabilization of the developing carbocation (phenacyl effect) is confirmed on visual inspection of the 3-D structure of cinnamyl chloride $\left(\mathbf{1}^{\prime}\right)$, shown in Figure 3, due to the perfect planarity of the ring and the adjacent vinylic double bond.

The previously reported specific rates of solvolysis at $25^{\circ} \mathrm{C}$ for cinnamyl bromide (2) [24] are analyzed using (1)(4). These results are reported in Table 3 for all 37 solvents and results are also tabulated for those obtained without the pure $\mathrm{EtOH}$ value (36 solvents). The slight improvements (for both 1 and 2) seen in the $R$ and the $F$-test values on exclusion of the specific rates in $100 \mathrm{EtOH}$, and the similarities in trends observed in the numerical values for $l$, $m$, and $h$, (reported in Tables 2 and 3 ) for $\mathbf{1}$ and 2 in thirty identical solvents are substantiated by the linear plot shown in Figure 4 of the $\log \left(k / k_{0}\right)$ values for 1 against those for 2 , with an excellent correlation coefficient of $0.989, F$-test value of 1201 , slope of $0.99 \pm 0.03$, and intercept of -0.02 \pm 0.05 . We can thus conclude that both, cinnamyl chloride and cinnamyl bromide solvolyze with nucleophilc solvation of the developing resonance-stabilized $S_{N} 1$ transition state. 
TABle 1: Specific rates of solvolysis $(k)^{a}$ of 1 , in several binary solvents at $25.0^{\circ} \mathrm{C}$ and literature values for $\left(N_{T}\right)$ and $\left(Y_{C l}\right)$.

\begin{tabular}{lccc}
\hline Solvent $(\%)^{\mathrm{b}}$ & $1 @ 25.0^{\circ} \mathrm{C} ; 10^{5} k, \mathrm{~s}^{-1}$ & $N_{T}^{l}$ & $Y_{\mathrm{Cl}}^{m}$ \\
\hline $100 \% \mathrm{MeOH}$ & 0.905 & 0.17 & -1.2 \\
$90 \% \mathrm{MeOH}$ & 4.87 & -0.01 & -0.20 \\
$80 \% \mathrm{MeOH}$ & 21.5 & -0.06 & 0.67 \\
$100 \% \mathrm{EtOH}$ & $0.416^{\mathrm{c}}$ & 0.37 & -2.50 \\
$90 \% \mathrm{EtOH}$ & $2.28^{\mathrm{d}}$ & 0.16 & -0.90 \\
$80 \% \mathrm{EtOH}$ & $8.05^{\mathrm{e}}$ & 0.00 & 0.00 \\
$90 \% \mathrm{Acetone}$ & 0.00731 & -0.35 & -2.39 \\
$97 \% \mathrm{TFE}(\mathrm{w} / \mathrm{w})$ & $488^{\mathrm{f}}$ & -3.30 & 2.83 \\
$90 \% \mathrm{TFE}(\mathrm{w} / \mathrm{w})$ & $626^{\mathrm{g}}$ & -2.55 & 2.85 \\
$80 \mathrm{~T}-20 \mathrm{E}$ & $83.5^{\mathrm{h}}$ & -1.76 & 1.89 \\
$60 \mathrm{~T}-40 \mathrm{E}$ & $14.5^{\mathrm{i}}$ & -0.94 & 0.63 \\
$40 \mathrm{~T}-60 \mathrm{E}$ & $3.52^{\mathrm{j}}$ & -0.34 & -0.48 \\
$20 \mathrm{~T}-80 \mathrm{E}$ & $1.12^{\mathrm{k}}$ & 0.08 & -1.42 \\
\hline
\end{tabular}

${ }^{\mathrm{a}}$ Determined titrimetrically; typical error $\pm 4 \%$. ${ }^{\mathrm{b}}$ Substrate concentration of $c$. $0.0052 \mathrm{M}$; binary solvents on a volume-volume basis at $25.0^{\circ} \mathrm{C}$, except for TFE- $\mathrm{H}_{2} \mathrm{O}$ solvents which are on a weight-weight basis. T-E are TFEethanol mixtures. ${ }^{c}$ Value reported in Table 1 is the average obtained using $\left.10^{5} \mathrm{k}^{-1} \mathrm{~s}^{-1}\right)$ values at $25.0^{\circ} \mathrm{C}$ of $0.409,0.420,0.418$, and 0.417 from four independent runs. A value of $0.0839 \times 10^{-5} \mathrm{~s}^{-1}$ is reported in the literature [23]. ${ }^{\mathrm{d}}$ Value reported in Table 1 is the average obtained using $10^{5} \mathrm{k}\left(\mathrm{s}^{-1}\right)$ values at $25.0^{\circ} \mathrm{C}$ of $2.26,2.27,2.30$, and 2.30 from four independent runs. A value of $0.970 \times 10^{-5} \mathrm{~s}^{-1}$ is reported in the literature [23]. ${ }^{\mathrm{e}}$ Value reported in Table 1 is the average obtained using $10^{5} \mathrm{k}^{\left(\mathrm{s}^{-1}\right)}$ values at $25.0^{\circ} \mathrm{C}$ of 8.03 , $8.03,8.03$, and 8.11 from four independent runs. A value of $4.73 \times 10^{-5} \mathrm{~s}^{-1}$ has been reported in the literature [23]. ${ }^{\mathrm{f}}$ Calculated from Arrhenius plots using $10^{5} \mathrm{k}\left(\mathrm{s}^{-1}\right)$ values at $0.0^{\circ},-5.0^{\circ}$, and $-10.0^{\circ} \mathrm{C}$ of $17.8,8.9$, and 4.0 . ${ }^{g}$ Calculated from Arrhenius plots using $10^{5} k\left(\mathrm{~s}^{-1}\right)$ values at $0.0^{\circ},-5.0^{\circ}$, and $-10.0^{\circ} \mathrm{C}$ of $23.9,10.2$, and 5.4. hValue reported in Table 1 is the average obtained using $10^{5} \mathrm{k}\left(\mathrm{s}^{-1}\right)$ values at $25.0^{\circ} \mathrm{C}$ of $82.7,83.1,83.8$, and 84.2 from four independent runs. A value of $84.8 \times 10^{-5}$ is reported in the literature

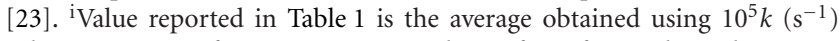
values at $25.0^{\circ} \mathrm{C}$ of $14.1,14.6,14.6$, and 14.7 from four independent runs. A value of $10.4 \times 10^{-5}$ is reported in the literature [23]. jValue reported in Table 1 is the average obtained using $10^{5} \mathrm{k}^{\left(\mathrm{s}^{-1}\right)}$ values at $25.0^{\circ} \mathrm{C}$ of 3.48 , $3.50,3.55$, and 3.56 from four independent runs. A value of $1.91 \times 10^{-5}$ is reported in the literature [23]. ${ }^{\mathrm{k}}$ Value reported in Table 1 is the average obtained using $10^{5} \mathrm{k}\left(\mathrm{s}^{-1}\right)$ values at $25.0^{\circ} \mathrm{C}$ of $1.09,1.10,1.13$, and 1.14 from four independent runs. A value of $0.353 \times 10^{-5}$ is reported in the literature [23]. ${ }^{1}$ Refs. $[9,10] .{ }^{\mathrm{m}}$ Refs. $[5,6]$.

Koo's claim [24, 33] of the presence of a through conjugation of the ring $\pi$ system with the reaction center in phenyl chlorothionoformate ( $\mathrm{PhOCSCl}$ ) was invalidated [34] lately as no evidence was found requiring inclusion of the $h$ parameter for ionization reactions with only one aromatic ring on the nitrogen of carbamoyl chlorides, or for the solvolyses of the chloroformate, or chlorothionoformate proceeding by an addition-elimination (associationdissociation) mechanism.

The 3-D views for cinnamoyl chloride $\left(\mathbf{3}^{\prime}\right)$ and $p$ nitrocinnamoyl chloride $\left(\mathbf{5}^{\prime}\right)$ are shown in Figure 3 incorporating prior results [35] for the position of the halogen in the ground-state structure of acid chlorides. The 3-D images of $\mathbf{3}^{\prime}$ and $\mathbf{5}^{\prime}$ clearly attest to the planar conformation between the aromatic ring, the vinylic double bond, and the carbonyl group. Studies have shown that when cinnamoylbased structures were synthesized and characterized by a syn disposition of the carbonyl group with the vinylic double bond, they specifically inhibited the enzymatic reactions associated with HIV-1 integrase (IN) [36].

The specific rate order reported [29] for the three $p$ substituted cinnamoyl chlorides is $k(\mathbf{3})>k(\mathbf{4})>k(\mathbf{5})$ in the pure and binary aqueous mixtures of $\mathrm{EtOH}, \mathrm{MeOH}$, and acetone, and a broader rate order of $k(\mathbf{3})>k(\mathbf{4}) \gg k(\mathbf{5})$ is reported in the aqueous TFE and the TFE-EtOH mixtures. The substantial rate decrease (of over a factor of 100) from 3 to 5 in TFE, 97 TFE, and 90 TFE is attributed to the powerful inductive destabilizing ability of the $p$-nitro group when positive charge is developing at the reaction center, due to the coplanarity observed between the ring, the vinylic double bond, and the reaction center in the 3-D view of $\mathbf{5}\left(\mathbf{5}^{\prime}\right.$ in Figure 3).

For a meaningful comparison of the application of (1)(4) to the specific rates of solvolysis of $\mathbf{3}, \mathbf{4}$, and 5 [29], it is important that the comparisons are made in identical solvents. A close examination of the data presented in Table 4 shows that for the three substrates in 24 common solvents, applications of (1) and (3) (without the $l N_{\mathrm{T}}$ term) gave exceedingly poor correlation coefficients $(R)$ and $F$-test values. This indicates that the correlations are very sensitive to solvent nucleophilicity, with a possibility for the further need of nucleophilic solvation $[2,17,30,31,34,37,38]$ of the developing transition state.

For compound 3 in the 24 solvents studied, use of (2) gives rise to an $l$ value of $0.19 \pm 0.06$ with a probability of 0.01 that the $l N$ term is statistically insignificant; an $m$ value of $0.49 \pm 0.05 ;-0.12 \pm 0.06$ for $c$; a correlation coefficient of 0.940 and an F-test of 80 . On application of (4) to the 24 solvents studied for 3 , there is a slight improvement in the value of $R$ to $0.956, l=0.31 \pm 0.07, m=0.56 \pm 0.05, h=0.48$ \pm 0.19 with a 0.02 probability that the $h I$ term is statistically insignificant, $c=-0.12 \pm 0.06$, and a $F$-test value of 70 . With compound 4, use of (2) in the identical 24 solvents used in the calculations for 3 , yields $l=0.33 \pm 0.05, m=0.59 \pm 0.04$, $c=-0.04 \pm 0.06, R=0.961$, and $F$-test $=128$. Essentially no improvements are observed with the use of (4) (for 3 ), where $l=0.36 \pm 0.07, m=0.60 \pm 0.05, h=0.12 \pm 0.19, c=-0.04$ $\pm 0.06, R=0.962$, and $F$-test $=83$. Use of (2) or (4) does not improve the immense scatter seen in the Grunwald-Winstein plots with the use of (1) or (3) for 5. Employing equation (2) for the same 24 solvents studied with 5 produces an $l$ value of $0.55 \pm 0.08, m=0.51 \pm 0.06, c=0.02 \pm 0.08, R=0.894$, and $F$-test $=42$. Application of (4) to the 24 solvents used with 5 shows no change in the scatter with $l=0.63 \pm 0.11, m=0.57$ $+0.04, h=-0.08 \pm 0.29, c=-0.02 \pm 0.08, R=0.961$, and $F$-test $=128$.

There has been considerable discussion regarding the reactivity-selectivity trends in aqueous TFE and TFE-EtOH [39-41]. Additionally, for a number of substrates [2, 34, 4248], there have been several instances where removal of the TFE-EtOH points has led to a considerable improvement of the goodness-of-fit parameters in Grunwald-Winstein linear free energy plots. Also presented in Table 4 are our correlation analysis results for $\mathbf{3}, \mathbf{4}$, and $\mathbf{5}$, with the exclusion of the data points in TFE-EtOH. This was done in order to evaluate the phenomena of dispersion commonly seen 
TABLE 2: Correlation of the specific rates of reaction of 1 , at $25.0^{\circ} \mathrm{C}$ using equations (1)-(4).

\begin{tabular}{|c|c|c|c|c|c|c|c|}
\hline Substrate & $S n^{\mathrm{a}}$ & $l^{\mathrm{b}}$ & $m^{\mathrm{b}}$ & $h^{\mathrm{b}}$ & $c^{\mathrm{c}}$ & $R^{\mathrm{d}}$ & $F^{\mathrm{e}}$ \\
\hline \multirow[t]{12}{*}{$1 ; 25.0^{\circ} \mathrm{C}$} & $32^{\mathrm{f}}$ & & $0.76 \pm 0.03$ & & $-0.25 \pm 0.08$ & 0.975 & 571 \\
\hline & & $\begin{array}{c}0.09 \pm 0.09 \\
(0.29)^{\mathrm{g}}\end{array}$ & $0.79 \pm 0.04$ & & $-0.21 \pm 0.09$ & 0.976 & 288 \\
\hline & & & $0.79 \pm 0.03$ & $\begin{array}{c}0.47 \pm 0.20 \\
(0.03)^{\mathrm{g}}\end{array}$ & $-0.30 \pm 0.08$ & 0.979 & 331 \\
\hline & & $0.33 \pm 0.08$ & $0.91 \pm 0.04$ & $0.97 \pm 0.21$ & $-0.20 \pm 0.07$ & 0.987 & 340 \\
\hline & $31^{\mathrm{h}}$ & & $0.79 \pm 0.03$ & & $-0.33 \pm 0.08$ & 0.979 & 664 \\
\hline & & $\begin{array}{c}0.09 \pm 0.08 \\
(0.26)^{\mathrm{g}}\end{array}$ & $0.82 \pm 0.04$ & & $-0.29 \pm 0.09$ & 0.980 & 337 \\
\hline & & & $0.82 \pm 0.03$ & $0.49 \pm 0.17$ & $-0.38 \pm 0.07$ & 0.984 & 416 \\
\hline & & $0.33 \pm 0.06$ & $0.95 \pm 0.03$ & $1.00 \pm 0.16$ & $-0.29 \pm 0.06$ & 0.992 & 551 \\
\hline & $30^{\mathrm{i}}$ & & $0.73 \pm 0.03$ & & $-0.15 \pm 0.08$ & 0.977 & 594 \\
\hline & & $\begin{array}{c}0.06 \pm 0.10 \\
(0.53)^{\mathrm{g}}\end{array}$ & $0.74 \pm 0.04$ & & $-0.13 \pm 0.09$ & 0.978 & 291 \\
\hline & & & $0.75 \pm 0.03$ & $\begin{array}{c}0.37 \pm 0.19 \\
(0.07)^{\mathrm{g}}\end{array}$ & $-0.21 \pm 0.08$ & 0.980 & 327 \\
\hline & & $0.36 \pm 0.11$ & $0.90 \pm 0.05$ & $0.88 \pm 0.23$ & $-0.15 \pm 0.07$ & 0.986 & 295 \\
\hline
\end{tabular}

${ }^{a}$ Using data at $25.0^{\circ} \mathrm{C}$ from Table $1 ; N_{\mathrm{T}}$ values from refs. [9, 10]; $Y_{\mathrm{Cl}}$ values from refs. [5, 6]; the 70-0\% MeOH, 80-10\% Acetone, 100TFE, 70TFE(w/w), $50 \mathrm{TFE}(\mathrm{w} / \mathrm{w})$ values are from reference [23]; $n$ is the number of solvents. ${ }^{\mathrm{b}}$ With associated standard error. ${ }^{\mathrm{c}}$ Accompanied by standard error of the estimate. ${ }^{\mathrm{d}}$ Correlation coefficient. ${ }^{\mathrm{e}} \mathrm{F}$-test value. ${ }^{\mathrm{f}}$ All solvents. ${ }^{\mathrm{g} P r o b a b i l i t y}$ that the contribution to the linear free energy relationship is insignificant. ${ }^{\mathrm{h}}$ Excluding $100 \mathrm{EtOH} .{ }^{\mathrm{i}}$ In exactly the same solvents as 2 .

TABLE 3: Correlation of the specific rates of reaction of 2 , at $25.0^{\circ} \mathrm{C}$ using equations (1)-(4).

\begin{tabular}{|c|c|c|c|c|c|c|c|}
\hline$\frac{\text { Substrate }}{2 ; 25.0^{\circ} \mathrm{C}}$ & $n^{\mathrm{a}}$ & $l^{\mathrm{b}}$ & $m^{\mathrm{b}}$ & $h^{\mathrm{b}}$ & $c^{c}$ & $R^{\mathrm{d}}$ & $F^{\mathrm{e}}$ \\
\hline \multirow[t]{12}{*}{$2 ; 25.0^{\circ} \mathrm{C}$} & $37^{f}$ & & $0.76 \pm 0.03$ & & $-0.15 \pm 0.08$ & 0.973 & 616 \\
\hline & & $\begin{array}{c}0.14 \pm 0.10 \\
(0.17)^{\mathrm{g}}\end{array}$ & $0.79 \pm 0.04$ & & $-0.11 \pm 0.08$ & 0.974 & 317 \\
\hline & & & $0.79 \pm 0.04$ & $\begin{array}{c}0.33 \pm 0.21 \\
\quad(0.12)^{\mathrm{g}}\end{array}$ & $-0.20 \pm 0.08$ & 0.975 & 323 \\
\hline & & $0.51 \pm 0.11$ & $1.01 \pm 0.05$ & $1.13 \pm 0.24$ & $-0.13 \pm 0.06$ & 0.985 & 354 \\
\hline & $36^{\mathrm{h}}$ & & $0.78 \pm 0.03$ & & $-0.20 \pm 0.08$ & 0.972 & 577 \\
\hline & & $\begin{array}{c}0.13 \pm 0.09 \\
(0.17)^{\mathrm{g}}\end{array}$ & $0.81 \pm 0.04$ & & $-0.16 \pm 0.09$ & 0.973 & 298 \\
\hline & & & $0.81 \pm 0.03$ & $\begin{array}{c}0.37 \pm 0.20 \\
\quad(0.08)^{\mathrm{g}}\end{array}$ & $-0.26 \pm 0.08$ & 0.974 & 311 \\
\hline & & $0.54 \pm 0.10$ & $1.05 \pm 0.05$ & $1.23 \pm 0.21$ & $-0.20 \pm 0.06$ & 0.987 & 403 \\
\hline & $30^{\mathrm{i}}$ & & $0.75 \pm 0.04$ & & $-0.17 \pm 0.09$ & 0.970 & 440 \\
\hline & & $\begin{array}{c}0.11 \pm 0.11 \\
(0.30)^{\mathrm{g}}\end{array}$ & $0.78 \pm 0.05$ & & $-0.12 \pm 0.10$ & 0.971 & 222 \\
\hline & & & $0.78 \pm 0.04$ & $\begin{array}{c}0.40 \pm 0.23 \\
\quad(0.09)^{\mathrm{g}}\end{array}$ & $-0.23 \pm 0.09$ & 0.973 & 238 \\
\hline & & $0.49 \pm 0.12$ & $1.00 \pm 0.06$ & $1.14 \pm 0.26$ & $-0.15 \pm 0.07$ & 0.983 & 255 \\
\hline
\end{tabular}

${ }^{a}$ Using data at $25.0^{\circ} \mathrm{C}$ from [24]; $N_{\mathrm{T}}$ values from $[9,10] ; Y_{\mathrm{Br}}$ values from [6]; $n$ is the number of solvents. ${ }^{\mathrm{b}}$ With associated standard error. ${ }^{\mathrm{c}}{ }^{\mathrm{Accompanied}}$ by standard error of the estimate. ${ }^{\mathrm{d}}$ Correlation coefficient. ${ }^{\mathrm{e}} \mathrm{F}$-test value. ${ }^{\mathrm{f}}$ All solvents. ${ }^{\mathrm{g}}$ Probability that the contribution to the linear free energy relationship is insignificant. ${ }^{\mathrm{h}}$ Excluding $100 \mathrm{EtOH} .{ }^{\mathrm{i}}$ In exactly the same solvents as $\mathbf{1}$.

for the TFE-EtOH solvents [39-41] and this observation is probably due to the bulky nature of this solvent (when compared to aqueous TFE) [43]. In the case of the solvolysis of 3, omission of the two TFE-EtOH solvents (22 solvents), and use of (2) yield $l=0.17 \pm 0.06$ associated with a 0.01 probability of statistical insignificance, $m=0.49 \pm 0.05$, $c=-0.10 \pm 0.06, R=0.945$, and $F$-test $=80$. There is considerable improvement of the goodness-of-fit parameters on application of (4) to the specific rates of solvolysis of $\mathbf{3}$ in 22 solvents. The significant improvement of $R=0.982$, and 


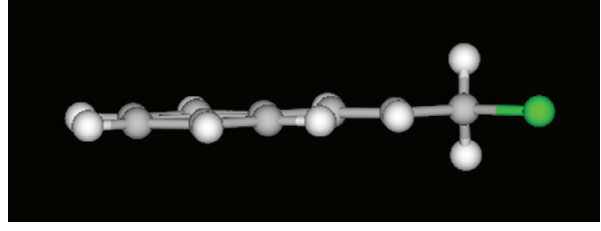

$1^{\prime}$

(a)

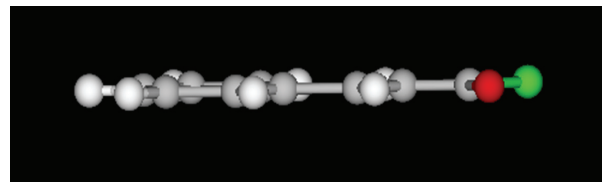

$3^{\prime}$

(b)

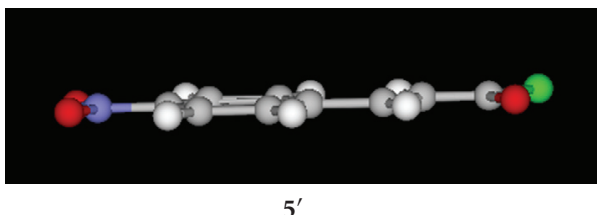

(c)

Figure 3: 3-D views of cinnamyl chloride $\left(\mathbf{1}^{\prime}\right)$, cinnamoyl chloride $\left(\mathbf{3}^{\prime}\right)$, and $p$-nitrocinnamoyl chloride $\left(\mathbf{5}^{\prime}\right)$, computed using the KnowItAll platform.

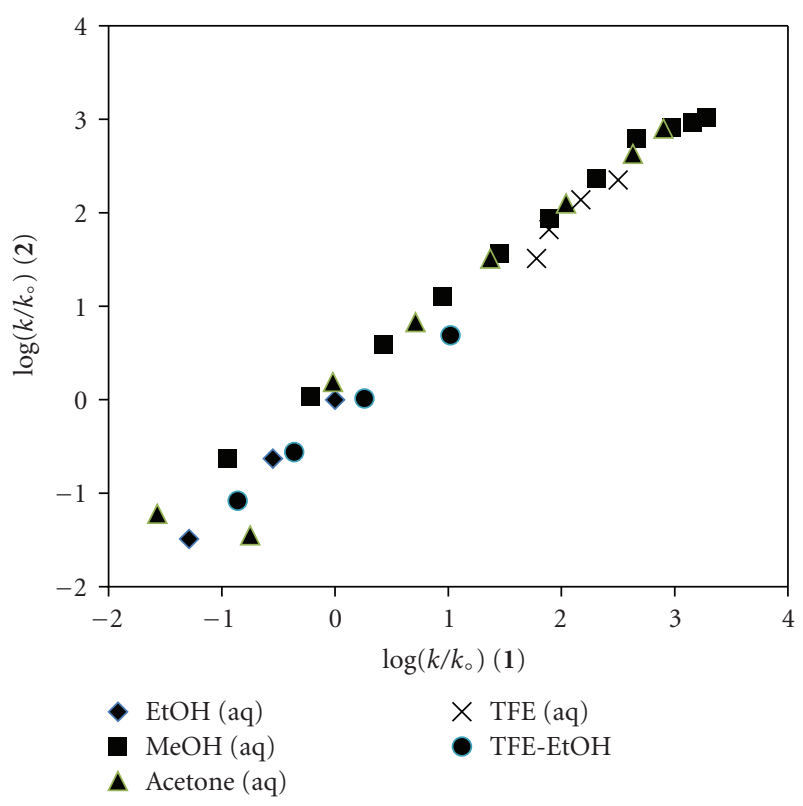

FIGURE 4: A plot of $\log \left(k / k_{o}\right)$ for cinnamyl bromide (2) against $\log$ $\left(k / k_{o}\right)$ for cinnamyl chloride $(\mathbf{1})$ in pure and binary solvents at $25^{\circ} \mathrm{C}$. This plot has a correlation coefficient of $0.989, F$-test value of 1201 , slope of $0.99 \pm 0.03$, and intercept of $-0.02 \pm 0.05$.

F-test $=163$, suggests that there is a need for nucleophilic solvation of the developing resonance stabilized carbocation with $l=0.37 \pm 0.05, m=0.60 \pm 0.03, h=0.89 \pm 0.15$, and $c=$ $-0.08 \pm 0.04$. The similarities of the $l, m$, and $h$ values (Tables 2 and 4) between cinnamyl (1) and cinnamoyl (3) chloride further suggest that the presence of a carbonyl oxygen has no major impact on either the amount of nucleophilic solvation needed to stabilize the developing carbocation or the amount of charge delocalized into the ring.

Analysis using (2) for the identical 22 solvents in solvolyses of 4 produces $l=0.30 \pm 0.04, m=0.58+0.03$, $c=-0.02 \pm 0.05, R=0.975$, and F-test $=187$. Use of $(4)$ improves the correlation coefficient significantly to 0.987 and the $F$-test is raised to 221 . The values of $l=0.43+0.04$, $m=0.64 \pm 0.03, h=0.53 \pm 0.14$, and $c=-0.01 \pm 0.04$, observed for 4 in the 22 solvents indicate a slightly higher need for nucleophilic solvation (when compared to 3 ) due to the destabilizing effect caused by the presence of a chlorine atom in the para position. This destabilization also impacts the amount of charge delocalization into the ring resulting in a lower $h$ value. The destabilizing effect is amplified in $\mathbf{5}$ due to the existence of a more powerful inductive effect due to the presence of the electron-withdrawing nitro group at the para position. The efficiency of transmission of the destabilizing electronic effects in $\mathbf{5}$ is made possible due to the complete coplanarity (as shown in the $3-\mathrm{D}$ image, $\mathbf{5}^{\prime}$ ) between the nitro group, the aromatic ring, the vinylic double bond, and the carbonyl group. At the other end of the spectrum, it was shown [49] that the observed specific rate order of $k_{p \text {-nitrophenyl chloroformate }}>k_{p \text {-nitrobenzyl chloroformate }}$ is due in part to the $p$-nitrobenzyl group twisting out of the plane with its ether oxygen and therefore being able to exert only a fraction of its inductive ability.

In the 22 solvents for the solvolyses of 5 , application of (2) yield, $l=0.61 \pm 0.06, m=0.49 \pm 0.04, c=0.07 \pm 0.06$, $R=0.941$, and $F$-test $=73$, and application of (4) leads to $l=0.74 \pm 0.07, m=0.56 \pm 0.04, h=0.56 \pm 0.20(0.01$ probability of statistical insignificance), $c=-0.08 \pm 0.05$, $R=0.959$, and $F$-test $=68$. Such large $l$ values have been observed in the unimolecular solvolysis of other structurally diverse acid chlorides $[2,48]$ and are indicative of the need for appreciable solvation of the developing carbocation plus a more facile approach of the solvent to an initially $\mathrm{sp}^{2}$-carbon than to an initially $\mathrm{sp}^{3}$-carbon.

\section{Conclusions}

In the present study we demonstrate that dispersions observed in Grunwald-Winstein correlations of the unimolecular solvolyses of substrates containing an adjacent $\pi$-electrons can be very well corrected by addition of an $h I$ term. For the cinnamyl and cinnamoyl halides studied, 
TABLE 4: Correlation of the specific rates of reaction of 3,4 , and 5 , at $25.0^{\circ} \mathrm{C}$ using equations (1)-(4).

\begin{tabular}{|c|c|c|c|c|c|c|c|}
\hline Substrate & $n^{\mathrm{a}}$ & $l^{\mathrm{b}}$ & $m^{\mathrm{b}}$ & $h^{\mathrm{b}}$ & $c^{c}$ & $R^{\mathrm{d}}$ & $F^{\mathrm{e}}$ \\
\hline \multirow[t]{4}{*}{$3 ; 25.0^{\circ} \mathrm{C}$} & $24^{\mathrm{f}}$ & & $0.39 \pm 0.04$ & & $-0.17 \pm 0.07$ & 0.913 & 110 \\
\hline & & $\begin{array}{c}0.19 \pm 0.06 \\
(0.01)^{\mathrm{g}}\end{array}$ & $0.49 \pm 0.05$ & & $-0.12 \pm 0.06$ & 0.940 & 80 \\
\hline & & & $0.40 \pm 0.04$ & $\begin{array}{c}-0.05 \pm 0.19 \\
(0.80)^{\mathrm{g}}\end{array}$ & $-0.17 \pm 0.07$ & 0.913 & 53 \\
\hline & & $0.31 \pm 0.07$ & $0.56 \pm 0.05$ & $\begin{array}{c}0.48 \pm 0.19 \\
(0.02)^{\mathrm{g}}\end{array}$ & $-0.12 \pm 0.06$ & 0.956 & 70 \\
\hline \multirow[t]{4}{*}{$4 ; 25.0^{\circ} \mathrm{C}$} & $24^{\mathrm{f}}$ & & $0.41 \pm 0.05$ & & $-0.14 \pm 0.09$ & 0.885 & 79 \\
\hline & & $0.33 \pm 0.05$ & $0.59 \pm 0.04$ & & $-0.04 \pm 0.06$ & 0.961 & 128 \\
\hline & & & $0.41 \pm 0.04$ & $\begin{array}{c}-0.51 \pm 0.21 \\
(0.02)^{\mathrm{g}}\end{array}$ & $-0.09 \pm 0.08$ & 0.911 & 52 \\
\hline & & $0.36 \pm 0.07$ & $0.60 \pm 0.05$ & $\begin{array}{c}0.12 \pm 0.19 \\
(0.56)^{\mathrm{g}}\end{array}$ & $-0.04 \pm 0.06$ & 0.962 & 83 \\
\hline \multirow[t]{4}{*}{$5 ; 25.0^{\circ} \mathrm{C}$} & $24^{\mathrm{f}}$ & & $0.18 \pm 0.08$ & & $-0.16 \pm 0.16$ & 0.411 & 5 \\
\hline & & $0.55 \pm 0.08$ & $0.51 \pm 0.06$ & & $0.02 \pm 0.08$ & 0.894 & 42 \\
\hline & & & $\begin{array}{c}0.17 \pm 0.07 \\
(0.02)^{\mathrm{g}}\end{array}$ & $-1.17 \pm 0.34$ & $-0.07 \pm 0.13$ & 0.683 & 9 \\
\hline & & $0.63 \pm 0.11$ & $0.50 \pm 0.07$ & $\begin{array}{c}-0.08 \pm 0.29 \\
(0.78)^{\mathrm{g}}\end{array}$ & $0.02 \pm 0.08$ & 0.895 & 27 \\
\hline \multirow[t]{4}{*}{$3 ; 25.0^{\circ} \mathrm{C}$} & $22^{\mathrm{h}}$ & & $0.40 \pm 0.04$ & & $-0.14 \pm 0.07$ & 0.922 & 114 \\
\hline & & $\begin{array}{c}0.17 \pm 0.06 \\
(0.01)^{\mathrm{g}}\end{array}$ & $0.49 \pm 0.05$ & & $-0.10 \pm 0.06$ & 0.945 & 80 \\
\hline & & & $0.40 \pm 0.04$ & $\begin{array}{c}0.14 \pm 0.22 \\
(0.53)^{\mathrm{g}}\end{array}$ & $-0.15 \pm 0.07$ & 0.924 & 56 \\
\hline & & $0.37 \pm 0.05$ & $0.60 \pm 0.03$ & $0.89 \pm 0.15$ & $-0.08 \pm 0.04$ & 0.982 & 163 \\
\hline \multirow[t]{4}{*}{$4 ; 25.0^{\circ} \mathrm{C}$} & $22^{\mathrm{h}}$ & & $0.42 \pm 0.04$ & & $-0.09 \pm 0.08$ & 0.911 & 97 \\
\hline & & $0.30 \pm 0.04$ & $0.58 \pm 0.03$ & & $-0.02 \pm 0.05$ & 0.975 & 187 \\
\hline & & & $0.41 \pm 0.04$ & $\begin{array}{c}-0.34 \pm 0.24 \\
(0.17)^{\mathrm{g}}\end{array}$ & $-0.08 \pm 0.08$ & 0.920 & 52 \\
\hline & & $0.43 \pm 0.04$ & $0.64 \pm 0.03$ & $0.53 \pm 0.14$ & $-0.01 \pm 0.04$ & 0.987 & 221 \\
\hline \multirow[t]{4}{*}{$5 ; 25.0^{\circ} \mathrm{C}$} & $22^{\mathrm{h}}$ & & $0.18 \pm 0.08$ & & $-0.07 \pm 0.15$ & 0.470 & 6 \\
\hline & & $0.61 \pm 0.06$ & $0.49 \pm 0.04$ & & $0.07 \pm 0.06$ & 0.941 & 73 \\
\hline & & & $\begin{array}{c}0.17 \pm 0.07 \\
(0.02)^{\mathrm{g}}\end{array}$ & $-0.91 \pm 0.40$ & $-0.05 \pm 0.13$ & 0.627 & 6 \\
\hline & & $0.73 \pm 0.07$ & $0.56 \pm 0.04$ & $\begin{array}{c}0.56 \pm 0.20 \\
\quad(0.01)^{\mathrm{g}}\end{array}$ & $0.08 \pm 0.05$ & 0.959 & 68 \\
\hline
\end{tabular}

a-e,g See footnotes in Table 1; ${ }^{\mathrm{f}}$ Data from [29], no 40E, $40 \mathrm{M}$ values for 5 ; ${ }^{\mathrm{h}}$ No T-E mixtures.

a stepwise ionization mechanism is proposed to be operating with the need for nucleophilic solvation of a resonancestabilized carbocation. The $h$ values of $\sim 1.00$ in cinnamyl chloride (1), cinnamyl bromide (2), and cinnamoyl chloride (3) are also consistent with one aromatic ring easily entering into conjugation with the developing resonance stabilized transition state. In cinnamoyl chlorides, electron withdrawing inductive effects ( $p$-chloro and $p$-nitro substituents) decrease the charge delocalized into the ring (lower $h$ value) and increase the need for nucleophilic solvation of the carbocation (higher $l$ value).

\section{Experimental Section}

The cinnamyl chloride was purchased from the SigmaAldrich chemical company and was used as received. Solvents were purified and the kinetic runs carried out as described previously [42]. A substrate concentration of approximately $0.005 \mathrm{M}$ in a variety of solvents was employed. The specific rates and associated standard deviations, as presented in Table 1, are obtained by averaging all of the values from, at least, duplicate runs. Multiple regression analyses were carried out using the Excel 2007 package from the Microsoft 
Corporation, and the 3D-views presented in Figure 3 for three of the five molecules used in this study were computed using the KnowItAll Informatics System, ADME/Tox Edition, from Bio-Rad Laboratories, Philadelphia, PA.

\section{Acknowledgments}

This research was supported by Grant no. 2 P2O RR01647210 from the National Center for Research Resources (NCRRs), a component of the National Institutes of Health (NIH). This IDeA Network of Biomedical Research Excellence (INBRE) grant to the state of Delaware was obtained under the leadership of the University of Delaware, and the authors sincerely appreciate their efforts. Additionally, A. M. Darrington acknowledges the receipt of a Tuition Scholarship from the NASA Grant NNG05GO92H Delaware Space Grant College and Fellowship Program.

\section{References}

[1] E. Grunwald and S. Winstein, "The correlation of solvolysis rates," Journal of the American Chemical Society, vol. 70, no. 2, pp. 846-854, 1948.

[2] D. N. Kevill and M. J. D'Souza, "Sixty years of the GrunwaldWinstein equation: development and recent applications," Journal of Chemical Research, no. 2, pp. 61-66, 2008.

[3] P. v. R. Schleyer and R. D. Nicholas, "The reactivity of bridgehead compounds of adamantane," Journal of the American Chemical Society, vol. 83, no. 12, pp. 2700-2707, 1961.

[4] T. W. Bentley and P. v. R. Schleyer, "Medium effects on the rates and mechanisms of solvolytic reactions," Advances in Physical Organic Chemistry, vol. 14, pp. 32-40, 1977.

[5] T. W. Bentley and G. E. Carter, "The $\mathrm{S}_{\mathrm{N}} 2-\mathrm{S}_{\mathrm{N}} 1$ spectrum. 4 . The SN2 (intermediate) mechanism for solvolyses of tert-butyl chloride: a revised $Y$ scale of solvent ionizing power based on solvolyses of 1-adamantyl chloride," Journal of the American Chemical Society, vol. 104, no. 21, pp. 5741-5747, 1982.

[6] T. W. Bentley and G. Llewellyn, " $Y_{x}$ scales of solvent ionizing power," Progress in Physical Organic Chemistry, vol. 17, pp. 121-158, 1990.

[7] S. Winstein, E. Grunwald, and H. Walter Jones, "The correlation of solvolysis rates and the classification of solvolysis reactions into mechanistic categories," Journal of the American Chemical Society, vol. 73, no. 6, pp. 2700-2707, 1951.

[8] S. Minegishi, S. Kobayashi, and H. Mayr, "Solvent nucleophilicity," Journal of the American Chemical Society, vol. 126, no. 16, pp. 5174-5181, 2004.

[9] D. N. Kevill, "Development and uses of scales of solvent nucleophilicity," in Advances in Quantitative Structure-Property Relationships, M. Charton, Ed., vol. 1, pp. 81-115, JAI Press, Greenwich, Conn, USA, 1996.

[10] D. N. Kevill and S. W. Anderson, "An improved scale of solvent nucleophilicity based on the solvolysis of the $S$ methyldibenzothiophenium ion," Journal of Organic Chemistry, vol. 56, no. 5, pp. 1845-1850, 1991.

[11] T. W. Bentley, I. S. Koo, and S. J. Norman, "Distinguishing between solvation effects and mechanistic changes. Effects due to differences in solvation of aromatic rings and alkyl groups," Journal of Organic Chemistry, vol. 56, no. 4, pp. 1604-1609, 1991.

[12] K.-T. Liu, "Nucleophilic solvent intervention in benzylic solvolyses. The use of $Y_{B n X}$ scales in Grunwald-Winstein type correlation analysis," Journal of The Chinese Chemical Society, vol. 42, pp. 607-615, 1995.

[13] K.-T. Liu and H.-C. Sheu, "Solvolysis of 2-aryl-2chloroadamantanes. A new $Y$ scale for benzylic chlorides," Journal of Organic Chemistry, vol. 56, no. 9, pp. 3021-3025, 1991.

[14] K.-T. Liu, Y.-S. Lin, and Y.-F. Duann, "Solvent effects on the solvolysis of some secondary tosylates. Applications of $Y_{\text {BnOTs }}$ and $Y_{x B n O T s}$ scales to mechanistic studies," Journal of the Chinese Chemical Society, vol. 50, no. 1, pp. 65-72, 2003.

[15] D. N. Kevill and M. J. D'Souza, “Concerning the development of scales of solvent ionizing power based on solvolyses of benzylic substrates," Journal of Physical Organic Chemistry, vol. 5, pp. 287-294, 1992.

[16] M. Fujio, Y. Saeki, K. Nakamoto, et al., "Solvent effects on anchimerically assisted solvolyses. II. Solvent effects in solvolyses of threo-2-aryl-1-methylpropyl-p-toluenesulfonates," Bulletin of the Chemical Society of Japan, vol. 68, pp. 2603-2617, 1995.

[17] D. N. Kevill, N. H. J. Ismail, and M. J. D’Souza, “Solvolysis of the ( $p$-methoxybenzyl)dimethylsulfonium ion. Development and use of a scale to correct for dispersion in GrunwaldWinstein plots," Journal of Organic Chemistry, vol. 59, no. 21, pp. 6303-6312, 1994.

[18] M. C. Reis, R. Elvas-Leitão, and F. Martins, "The influence of carbon-carbon multiple bonds on the solvolyses of tertiary alkyl halides: a grunwald-winstein analysis," International Journal of Molecular Sciences, vol. 9, no. 9, pp. 1704-1716, 2008.

[19] D. N. Kevill and M. J. D'Souza, "Use of the simple and extended Grunwald-Winstein equations in the correlation of the rates of solvolysis of highly hindered tertiary alkyl derivatives," Current Organic Chemistry, vol. 14, pp. 10371049, 2010.

[20] A. Goossens, S. Huygens, L. Stoskute, and J.-P. Lepoittevin, "Primary sensitization to cinnamyl chloride in an operator of a pharmaceutical company," Contact Dermatitis, vol. 55 , no. 6 , pp. 364-365, 2006.

[21] J.-I. Hayami, N. Tanaka, and A. Kaji, "SN2 Reactions in dipolar aprotic solvents. III. Chlorine isotopic exchange reactions of cinnamyl chlorides and 3-aryl-2-propynyl chlorides. Effect of the unsaturated group adjacent to the reaction center," Bulletin of the Chemical Society of Japan, vol. 46, pp. 954-959, 1973.

[22] J.-I. Hayami, N. Hihara, N. Tanaka, and A. Kaji, "SN2 reactions in dipolar aprotic solvents. VII. Kinetic and equilibrium secondary?-deuterium isotope effects in chlorine isotopic exchange reactions of substituted chloromethanes in acetonitrile," Bulletin of the Chemical Society of Japan, vol. 52, pp. 831-835, 1979.

[23] I. S. Koo, S. K. An, K. Yang, I. Lee, and T. W. Bentley, "Correlation of the rates of solvolyses of cinnamyl chloride," Journal of Physical Organic Chemistry, vol. 15, no. 11, pp. 758764, 2002.

[24] I. S. Koo, J. M. Cho, S. K. An, K. Yang, J. P. Lee, and I. Lee, "Correlation of the rates of solvolyses of cinnamyl bromide," Bulletin of the Korean Chemical Society, vol. 24, no. 4, pp. 431436, 2003.

[25] T. W. Bentley, G. Llewellyn, and Z. H. Ryu, "Solvolytic reactions in fluorinated alcohols. Role of nucleophilic and other solvation effects," Journal of Organic Chemistry, vol. 63, no. 14, pp. 4654-4659, 1998.

[26] D. K. Brown, J. L. Dean, W. X. Lopez, and C. Ji, "Electrochemical reduction of cinnamyl bromide at carbon cathodes 
in acetonitrile: a further mechanistic study," Journal of the Electrochemical Society, vol. 156, no. 10, pp. F123-F127, 2009.

[27] H. Marona, N. Szkaradek, E. Karczewska et al., "Antifungal and antibacterial activity of the newly synthesized 2-xanthone derivatives," Archiv der Pharmazie, vol. 342, no. 1, pp. 9-18, 2008.

[28] A. Senff-Ribeiro, A. Echevarria, E. F. Silva, C. R. C. Franco, S. S. Veiga, and M. B. M. Oliveira, "Cytotoxic effect of a new 1,3,4thiadiazolium mesoionic compound (MI-D) on cell lines of human melanoma," British Journal of Cancer, vol. 91, no. 2, pp. 297-304, 2004.

[29] I. S. Koo, J.-S. Kim, S. K. An, K. Yang, and I. Lee, "Kinetic studies on solvolyses of substituted cinnamoyl chlorides in alcohol-water mixtures," Journal of the Korean Chemical Society, vol. 43, pp. 527-534, 1999.

[30] D. N. Kevill and M. J. D'Souza, "Concerning the extents of nucleophilic participation in solvolyses of $p$-methoxybenzyl halides," Journal of Chemical Research S, no. 5, pp. 336-337, 1999.

[31] D. N. Kevill and M. J. D’Souza, “Correlation of the rates of solvolysis of benzoyl chloride and derivatives using extended forms of the Grunwald-Winstein equation," Journal of Physical Organic Chemistry, vol. 15, no. 12, pp. 881-888, 2002.

[32] J. D. Kim, G. Han, L. S. Jeong, H.-J. Park, O. P. Zee, and Y. H. Jung, "Study of the stability of carbocations by chlorosulfonyl isocyanate reaction with ethers," Tetrahedron, vol. 58, no. 22, pp. 4395-4402, 2002.

[33] I. S. Koo, K. Yang, D. H. Kang, H. J. Park, K. Kang, and I. Lee, "Transition-state variation in the solvolyses of phenyl chlorothionoformate in alcohol-water mixtures," Bulletin of the Korean Chemical Society, vol. 20, no. 5, pp. 577-580, 1999.

[34] D. N. Kevill, F. Koyoshi, and M. J. D'Souza, "Correlations of the specific rates of solvolysis of aromatic carbamoyl chlorides, chloroformates, chlorothionoformates, and chlorodithioformates revisited," International Journal of Molecular Sciences, vol. 8, no. 4, pp. 346-362, 2007.

[35] T. W. Bentley, "Structural effects on the solvolytic reactivity of carboxylic and sulfonic acid chlorides. Comparisons with gas-phase data for cation formation," Journal of Organic Chemistry, vol. 73, no. 16, pp. 6251-6257, 2008.

[36] M. Artico, R. D. Santo, R. Costi et al., "Geometrically and conformationally restrained cinnamoyl compounds as inhibitors of HIV-1 integrase: synthesis, biological evaluation, and molecular modeling," Journal of Medicinal Chemistry, vol. 41, no. 21, pp. 3948-3960, 1998.

[37] J. P. Richard and W. P. Jencks, "Reactions of substituted 1phenylethyl carbocations with alcohols and other nucleophilic reagents," Journal of the American Chemical Society, vol. 106, no. 5, pp. 1373-1383, 1984.

[38] J. P. Richard, M. M. Toteva, and T. L. Amyes, "What is the stabilizing interaction with nucleophilic solvents in the transition state for solvolysis of tertiary derivatives: nucleophilic solvent participation or nucleophilic solvation?" Organic Letters, vol. 3, no. 14, pp. 2225-2228, 2001.

[39] S. P. McManus, T. Crutcher, R. W. Naumann et al., "Selectivity in the solvolysis in binary solvents of 1-adamantyl derivatives bearing leaving groups that depart as neutral molecules," Journal of Organic Chemistry, vol. 53, no. 18, pp. 4401-4403, 1988.

[40] D. N. Kevill and S. W. Anderson, "Essentially solvent-independent rates of solvolysis of the 1-adamantyldimethylsulfonium ion. Implications regarding nucleophilic assistance in solvolyses of tert-butyl derivatives and the NKL solvent nucleophilicity scale," Journal of the American Chemical Society, vol. 108, no. 7, pp. 1579-1585, 1986.

[41] T. W. Bentley, "Nucleophilicites of aqueous, alcoholic, and acidic media," Advances in Chemistry, vol. 15, pp. 255-268, 1987.

[42] D. N. Kevill, Z. H. Ryu, M. A. Niedermeyer, F. Koyoshi, and M. J. D'Souza, "Rate and product studies in the solvolyses of methanesulfonic anhydride and a comparison with methanesulfonyl chloride solvolyses," Journal of Physical Organic Chemistry, vol. 20, no. 6, pp. 431-438, 2007.

[43] D. N. Kevill and B. Miller, "Application of the $N_{T}$ solvent nucleophilicity scale to attack at phosphorus: solvolyses of $N, N, N^{\prime}, N^{\prime}$-tetramethyldiamidophosphorochloridate," Journal of Organic Chemistry, vol. 67, no. 21, pp. 7399-7406, 2002.

[44] J. B. Kyong, S. H. Ryu, and D. N. Kevill, "Rate and product studies of solvolyses of benzyl fluoroformate," International Journal of Molecular Sciences, vol. 7, no. 7, pp. 186-196, 2006.

[45] H. J. Koh, S. J. Kang, and D. N. Kevill, "Reaction mechanism studies of solvolytic displacement of chloride from phosphorus," Phosphorus, Sulfur and Silicon and the Related Elements, vol. 183, no. 2-3, pp. 364-368, 2008.

[46] M. J. D’Souza, L. Yaakoubd, S. L. Mlynarski, and D. N. Kevill, "Concerted solvent processes for common sulfonyl chloride precursors used in the synthesis of sulfonamide-based drugs," International Journal of Molecular Sciences, vol. 9, no. 5, pp. 914-925, 2008.

[47] M. H. Seong, J. B. Kyong, Y. H. Lee, and D. N. Kevill, "Corrrelation of the specific rates of solvolysis of ethyl fluoroformate using the extended grunwald-winstein equation," International Journal of Molecular Sciences, vol. 10, no. 3, pp. 929-941, 2009.

[48] M. J. D’Souza, Z. H. Ryu, B.-C. Park, and D. N. Kevill, "Correlation of the rates of solvolysis of acetyl chloride and $\alpha$-substituted derivatives," Canadian Journal of Chemistry, vol. 86, no. 5, pp. 359-367, 2008.

[49] M. J. D’Souza, K. E. Shuman, S. E. Carter, and D. N. Kevill, "Extended Grunwald-Winstein analysis_LFER used to gauge solvent effects in p-nitrophenyl chloroformate solvolysis," International Journal of Molecular Sciences, vol. 9, no. 11, pp. 2231-2242, 2008. 


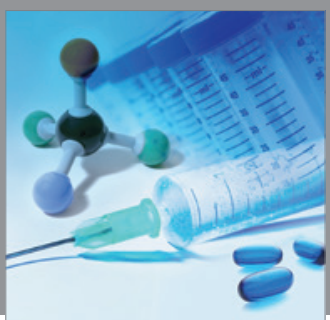

International Journal of

Medicinal Chemistry

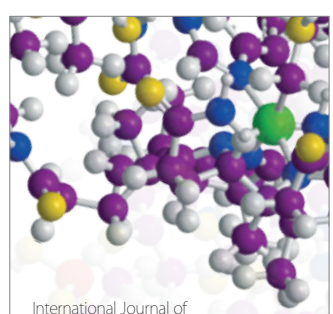

Carbohydrate Chemistry

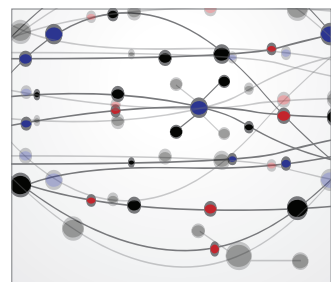

The Scientific World Journal
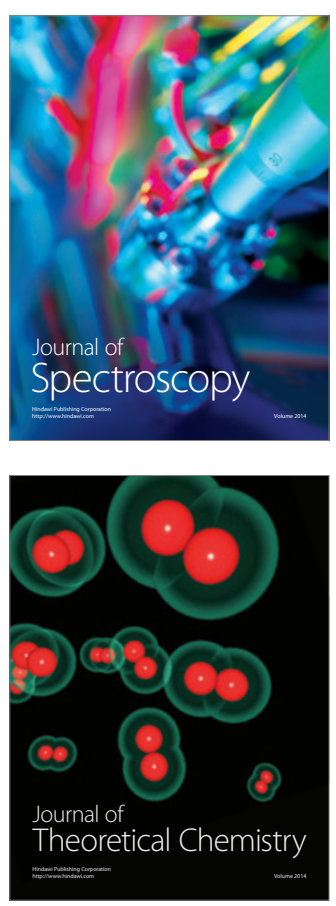
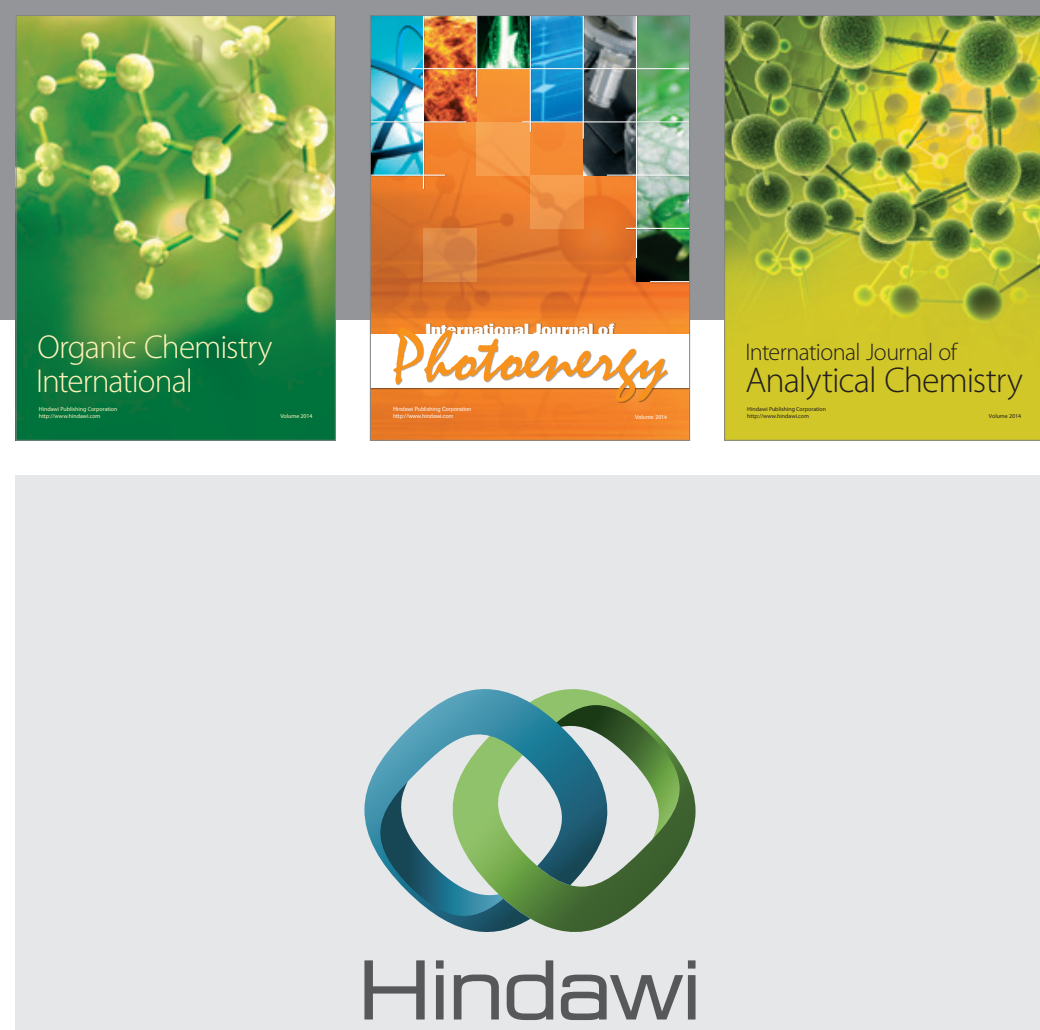

Submit your manuscripts at

http://www.hindawi.com
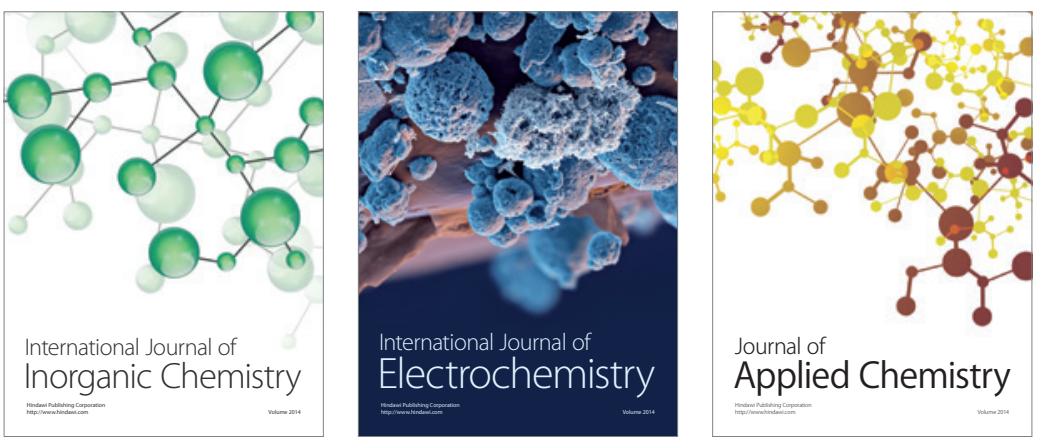

Journal of

Applied Chemistry
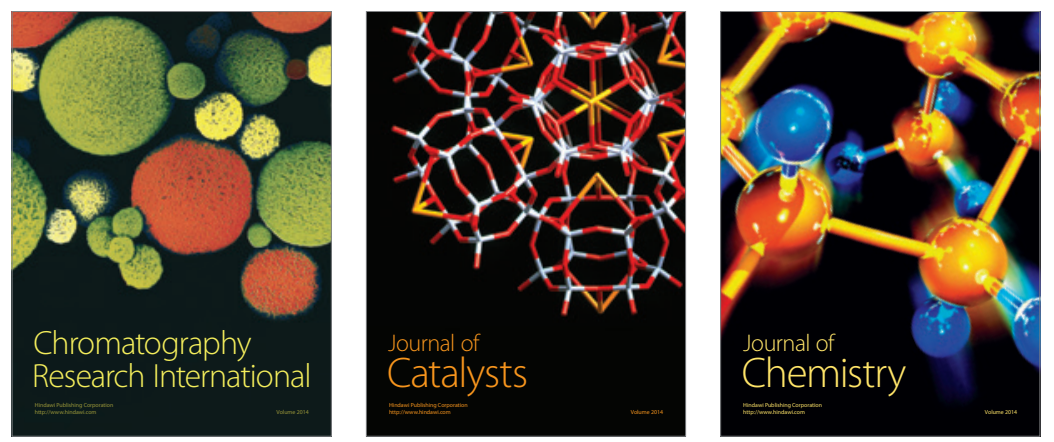
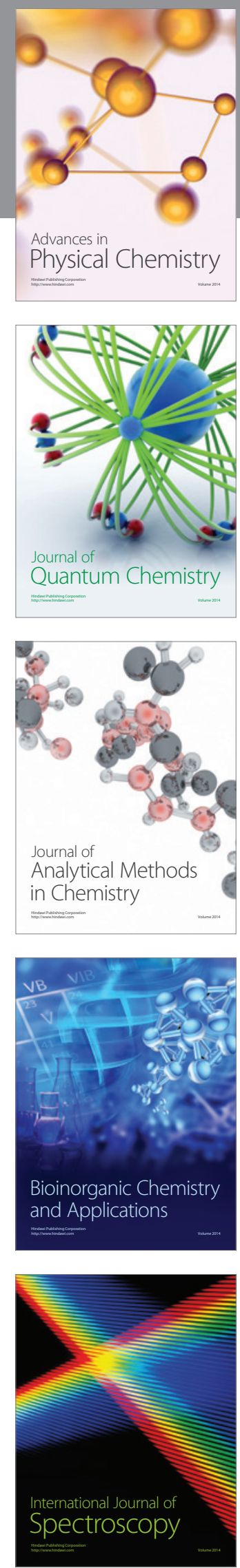